\title{
Application of phage typing and pulsed-field gel electrophoresis to analyse Salmonella enterica isolates from a suspected outbreak in Lagos, Nigeria
}

\author{
Kabir O. Akinyemi ${ }^{1}$,Werner Philipp ${ }^{2}$, Wolfgang Beyer ${ }^{2}$, Reinhard Böhm ${ }^{2}$ \\ ${ }^{1}$ Department of Microbiology, Lagos State University, Ojo, PMB 1087, Apapa, Lagos, Nigeria \\ ${ }^{2}$ Institüt für Umwelt und Tierhygiene - 460, Universität Hohenheim Garbenstr.30,70599,Stuttgart, Germany
}

\begin{abstract}
Introduction: Inadequate potable water supply and poor sanitation predispose to food- and water-borne diseases associated with Salmonella enterica serovars in developing countries. In this study the possible source of an unprecedented upsurge of Salmonella-associated community gastroenteritis was traced using both phage-typing and pulsed-field gel electrophoresis (PFGE).

Methodology: Nineteen Salmonella Typhimurium (three sporadic isolates included) and 13 Salmonella Enteritidis isolates from clinical, animal, and environmental samples were subjected to antimicrobial susceptibility testing, phage-typing, and PFGE analysis using standard procedures.

Results: Eleven $(68.8 \%)$ of the 16 outbreak-related multidrug resistant $S$. Typhimurium belonged to DT 71 phage type with cluster PFGE type X3, representing the most prevalent strain identified among human, animal, and environmental isolates. The remaining five (31.2\%) outbreak-related strains reacted but did not conform with clear phage types (RDNC) with cluster PFGE types X1 and X2 (96.8\% similarity). Sporadic strains were untypable and belonged to X4 PFGE type. However, the evaluated $S$. Enteritidis strains that were multidrug resistant without a definite phage type belonged to PFGE cluster type X1e and were identified among the water and human strains. None of the Typhimurium and Enteritdis isolates was resistant to the fluoroquinolone antibiotics that were evaluated.

Conclusion: This study emphasizes the epidemiological usefulness of PFGE typing in the detection of emerging strains of multipledrug resistant Salmonella, particularly $S$. Typhimurium DT71, that pose serious health implications in our environment. The study provides epidemiological links between environmental reservoirs and human infection in this community.
\end{abstract}

Key words: Salmonella; resistance; phage-typing; PFGE; human, environment

J Infect Dev Ctries 2010; 4(12):828-834.

(Received 11 December 2009 - Accepted 11 July 2010)

Copyright $\odot 2010$ Akinyemi et al. This is an open-access article distributed under the Creative Commons Attribution License, which permits unrestricted use, distribution, and reproduction in any medium, provided the original work is properly cited.

\section{Introduction}

Non-typhoidal salmonellosis is a major foodborne infection with an estimated annual incidence of 1.3 billion cases and over 2 million deaths worldwide [1]. Salmonella enterica serovars Typhimurium and Salmonella Enteritidis have now become the predominant serotypes in many countries over the past 10 years [2,3]. Most cases are associated with outbreaks from meat, dairy and poultry products, or by cross-contamination; however, sporadic cases also occur $[4,5]$. In Africa, well water and water from rivers or lakes are usually used for public consumption; therefore, contamination by raw sewage sometimes remains an important factor in the epidemiology of typhoidal and, in rare cases, nontyphoidal salmonellosis [6].

In Nigeria, salmonella-associated ailments have been documented in different geographical locations in clinical settings [7-10]. However, there are few reports on the circulating strains of non-typhoidal salmonellae and their significance, particularly S. Typhimurium and S. Enteritidis, in this environment. Traditionally, phenotypic methods such as serotyping, antibiogram, and phage typing have been used to characterize Salmonella isolates. Phage typing has been used with great success to trace the source of human salmonellosis [11-13]. A number of molecular typing techniques such as pulsed-field gel electrophoresis (PFGE), ribotyping, and restriction fragment length polymorphism (RFLP) have been used to identify and differentiate strains below the level of serotypes because of the reliability and high discriminating power of these methods, particularly during outbreaks [14]. Random amplified polymorphic DNA (RAPD) has high discriminatory powers; however, it has poor inter- and intralaboratory reproducibility [15]. PFGE has become the method of choice in the analyses of novel 
epidemic strains from salmonellosis outbreaks [16,17]. Basically, PFGE targets the intact and large chromosomal DNA embedded in an agarose plug, and that is why PFGE is capable of producing a more highly reproducible and reliable result than other methods in tracing the source of outbreaks $[14,16]$. In this study, we applied both phage typing and PFGE to investigate the diversity of $S$. Typhimurium and $S$. Enteritidis strains from humans, animals, and the environment in an upsurge of communityacquired Salmonella-associated illness in Lagos.

\section{Methodology}

Bacterial agents

Thirty-two Salmonella isolates from human, animals and the environment were evaluated in this study. Out of these, 21 were human isolates, 18 of which were collected during from clinically diagnosed patients during an unprecedented upsurge of Salmonella-associated gastroenteritis in Okokomaiko, Ojo community, of Lagos State between December 2004 and January 2005. The three remaining samples were sporadic isolates, collected in 1997, 1999, and 2002. Eight environmental isolates were identified from sewage or well waters within a 500-metre radius of the cases. All the well waters (the major source of drinking water in this area) were owned by private individuals and are usually open to the general public. The remaining three Salmonella isolates were from fresh faeces of cows reared by nomadic Fulani people in this area. Preliminary identification of the isolates was conducted by standard methods [18]. The isolates were maintained and stored at $-4^{\circ} \mathrm{C}$ in vials containing Muller-Hinton agar. The isolates were further identified biochemically using the API 20E System (BioMerieux, Marcy 1'Etoil, France) and serotyped according to the latest versions of the Kauffmann-White scheme [19].

\section{Antimicrobial susceptibility testing}

All Salmonella isolates were investigated for their in vitro susceptibilities to 13 antibiotics by both disk diffusion and microdilution assay per Clinical and Laboratory Standard Institute (CLSI; formerly NCCLS) guidelines [20]. The following antimicrobial agents (Sigma, Deisenhofen, Germany) were used for the tests: Ampicillin $(10 \mu \mathrm{g})$,

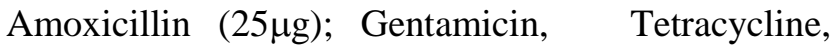
Chloramphenicol, Colistin-sulphate, Sulfomethoxazole-trimethoprim, Trimethoprim, Cefoperazone, Ofloxacin, Ciprofloxacin, Perfloxacin and Cefotaxime (A, Am, G, T, C, Sf, Tp, and Ce, respectively). E. coli ATCC 25922, Staphylococcus aureus ATCC 29213, and Enterococcus faecalis ATCC 29212 were used as controls.

\section{Phage typing}

The bacteriophage typing was performed at the Robert Koch Institute, Wernigerode, Germany, using the system of Ward et al. [11] as applied in the Central Public Health Laboratory, London, United Kingdom, for $S$. Enteritidis, and the scheme of Anderson et al. [21] for $S$. Typhimurium, with slight modifications based on over five decades of laboratory procedure adopted by the Koch Institute. Isolates were subjected to purity control by incubation on Endo agar plates [22]. Strains showing a pattern that did not conform to any recognized phage patterns were designated as "reacted but did not conform" (RDNC). Strains that did not react with any of the typing phages were designated as "untypeable" (UT).

\section{Pulsed-field gel electrophoresis}

PFGE was performed according to the standardized laboratory protocol for molecular subtyping of non-typhoidal Salmonella of Pulse-Net [23], with minor modifications as follows: $300 \mu \mathrm{l}$ of adjusted cell suspension was transferred to $1.5-\mathrm{ml}$ micro-centrifuge tubes with $15 \mu \mathrm{l}$ of proteinase $\mathrm{K}$ $(20 \mathrm{mg} / \mathrm{ml})$, and was subsequently mixed with $300 \mu \mathrm{l}$ of melted $1 \%$ SeaKem Gold (Cambrex, East Rutherford, N.J.) : $1 \%$ sodium dodecyl sulphate agarose prepared with TE buffer $(10 \mathrm{mM}$ Tris, $1 \mathrm{mM}$ EDTA, $\mathrm{pH}$ 8.0), and pipetted into disposable plug moulds. Digested DNA plugs were loaded into the wells containing $1 \%$ pulsed-field agarose certified (Bio-Rad, Dusseldorf, Germany) in 0.5 X TBE (0.9 $\mathrm{M}$ Tris base, $0.9 \mathrm{M}$ boric acid, 0.02 M EDTA, pH 8.0) extended range buffer (Bio-Rad, Dusseldolf, Germany). DNA from Salmonella Braenderup H9812 restricted with Xbal was used as a size marker. PFGE was performed on CHEF DR-II and CHEF DR-III (Bio-Rad, Dusseldorf, Germany), and running conditions were $6 \mathrm{~V} / \mathrm{cm}$ at $120^{\circ} \mathrm{C}$ for 19.5 and 19 hours for $S$. Enteritidis and $S$. Typhimurium respectively, and switching times ranged from $2.2 \mathrm{sec}$ to 63.8 sec. Gels were stained with $0.5 \mu \mathrm{l} / \mathrm{ml}$ ethidium bromide for one hour, destained in water, observed under UV light, and photographed. Macrorestriction patterns were compared with the use of GelComparII (Applied Maths, Sint-Martens-Latem, Belgium) software. 
Table 1. PFGE patterns, phage types and resistance profiles of Salmonella enterica serovars Typhimurium and Enteritidis from humans, animals and environment.

\begin{tabular}{|c|c|c|c|c|c|c|}
\hline Serotypes & $\begin{array}{l}\text { Isolation } \\
\text { number }\end{array}$ & $\begin{array}{l}\text { Period of } \\
\text { isolation } \\
(\text { Mth. , yr) })^{a}\end{array}$ & $\begin{array}{l}\text { Sample } \\
\text { source }\end{array}$ & Phage type & Xbal type & Antimicrobial resistance ${ }^{\mathrm{b}}$ \\
\hline S.Typhimurium & $\begin{array}{l}\text { NST-24 } \\
\text { NST-25 } \\
\text { NST-35 } \\
\text { NST-16 } \\
\text { NST-10 } \\
\text { NST-02 } \\
\text { NST-27 } \\
\text { NST-20 } \\
\text { NST-19 } \\
\text { NST-29 } \\
\text { NST-06 } \\
\text { NST-09 } \\
\text { NST-30 } \\
\text { NST-22 } \\
\text { NST-31 } \\
\text { NST-11 } \\
\text { *NST-04 } \\
{ }^{*} \text { NST-03 } \\
\text { *NST-14 }\end{array}$ & $\begin{array}{l}\text { Dec.,04 } \\
\text { Jan.,05 } \\
\text { Jan.,05 } \\
\text { Jan.,05 } \\
\text { Feb.,05 } \\
\text { Dec.,04 } \\
\text { Dec.,04 } \\
\text { Jan.,05 } \\
\text { Jan.,05 } \\
\text { Jan.,05 } \\
\text { Jan.,05 } \\
\text { Jan.,05 } \\
\text { Feb.,05 } \\
\text { Feb.,05 } \\
\text { Feb.,05 } \\
\text { Feb.,05 } \\
\text { Jul., } 97 \\
\text { Aug. } 99 \\
\text { Dec., } 02\end{array}$ & $\begin{array}{l}\text { Human } \\
\text { Human } \\
\text { Human } \\
\text { Human } \\
\text { Sewage } \\
\text { Human } \\
\text { Human } \\
\text { Human } \\
\text { Human } \\
\text { Human } \\
\text { Cattle } \\
\text { Cattle } \\
\text { Water } \\
\text { Water } \\
\text { Sewage } \\
\text { Sewage } \\
\text { Human } \\
\text { Human } \\
\text { Human }\end{array}$ & $\begin{array}{l}\text { RDNC } \\
\text { RDNC } \\
\text { RDNC } \\
\text { RDNC } \\
\text { RDNC } \\
\text { DT71 } \\
\text { DT71 } \\
\text { DT71 } \\
\text { DT71 } \\
\text { DT71 } \\
\text { DT71 } \\
\text { DT71 } \\
\text { DT71 } \\
\text { DT71 } \\
\text { DT71 } \\
\text { DT71 } \\
\text { UT } \\
\text { UT } \\
\text { UT }\end{array}$ & $\begin{array}{l}\mathrm{X} 1 \\
\mathrm{X} 1 \\
\mathrm{X} 2 \\
\mathrm{X} 2 \\
\mathrm{X} 2 \\
\mathrm{X} 3 \\
\mathrm{X} 3 \\
\mathrm{X} 3 \\
\mathrm{X} 3 \\
\mathrm{X} 3 \\
\mathrm{X} 3 \\
\mathrm{X} 3 \\
\mathrm{X} 3 \\
\mathrm{X} 3 \\
\mathrm{X} 3 \\
\mathrm{X} 3 \\
\mathrm{X} 4 \\
\mathrm{X} 4 \\
\mathrm{X} 4\end{array}$ & $\begin{array}{l}\text { A,Am,G,T,C,Ct,Sf,Tp,Ce } \\
\text { A,Am,G,T,C,Sf,Tp,Ce } \\
\text { A,Am,G,T,C,Ct,Sf,Tp,Ce } \\
\text { A,Am,G,T,C,Ct,Sf,Tp,Ce } \\
\text { A,Am,G,T,C,Sf,Tp,Ce } \\
\text { A,Am,T,C,Ct,Sf,Tp,Ce } \\
\text { A, G, T,C,Ct,Sf,Tp,Ce } \\
\text { G,T,C,Ct,Sf } \\
\text { G,T,C,Ct,Sf,Tp } \\
\text { Am,G,T,C,Ct,Sf,Tp } \\
\text { Am,G,T,C,Ct,Sf,Tp } \\
\text { G,T,C } \\
\text { G,T,C } \\
\text { G,T,C,Sf } \\
\text { A,G,T,C,Ct } \\
\text { G,T,C,Sf } \\
\text { A,T,C,Tp,Ce } \\
\text { A,G,T,C,Sf,Tp } \\
\text { G,T,C,Ct }\end{array}$ \\
\hline S.Enteritidis & $\begin{array}{l}\text { NST-34 } \\
\text { NST-23 } \\
\text { NST-18 } \\
\text { NST-33 } \\
\text { NST-28 } \\
\text { NST-17 } \\
\text { NST-15 } \\
\text { NST-01 } \\
\text { NST-26 } \\
\text { NST-05 } \\
\text { NST-07 } \\
\text { NST-08 } \\
\text { NST-21 }\end{array}$ & $\begin{array}{l}\text { Jan., 05 } \\
\text { Dec.,04 } \\
\text { Dec.,04 } \\
\text { Dec.,04 } \\
\text { Jan.,05 } \\
\text { Jan.,05 } \\
\text { Jan.,05 } \\
\text { Jan.,05 } \\
\text { Jan.,05 } \\
\text { Jan.,05 } \\
\text { Feb.,05 } \\
\text { Feb.,05 } \\
\text { Feb.,05 }\end{array}$ & $\begin{array}{l}\text { Human } \\
\text { Human } \\
\text { Human } \\
\text { Human } \\
\text { Human } \\
\text { Water } \\
\text { Human } \\
\text { Human } \\
\text { Human } \\
\text { Human } \\
\text { Water } \\
\text { Cattle } \\
\text { Water }\end{array}$ & $\begin{array}{l}\text { UT } \\
\text { RDNC } \\
\text { UT } \\
\text { RDNC } \\
\text { RDNC } \\
\text { UT } \\
\text { UT } \\
\text { UT } \\
\text { RDNC } \\
\text { RDNC } \\
\text { PT29 } \\
\text { RDNC } \\
\text { RDNC }\end{array}$ & $\begin{array}{l}X 1 \mathrm{e} \\
X 1 \mathrm{e} \\
\mathrm{X} 1 \mathrm{e} \\
\mathrm{X} 1 \mathrm{e} \\
\mathrm{X} 1 \mathrm{e} \\
\mathrm{X} 1 \mathrm{e} \\
\mathrm{X} 1 \mathrm{e} \\
\mathrm{X} 1 \mathrm{e} \\
\mathrm{X} 2 \mathrm{e} \\
\mathrm{X} 3 \mathrm{e} \\
\mathrm{X} 4 \mathrm{e} \\
\mathrm{X} 4 \mathrm{e} \\
\mathrm{X} 4 \mathrm{e}\end{array}$ & $\begin{array}{l}\text { A,Am,G,T,C,Ct,Sf,Tp,Ce,Cn } \\
\text { A,Am,G,T,C,Ct,Sf,Tp,Ce } \\
\text { A,Am,G,T,C,Ct,Sf,Tp,Ce } \\
\text { A,Am,T,C,Ct,Sf,Tp,Ce,Cn } \\
\text { A,Am,T,C,Ct,Sf,Tp,Ce } \\
\text { A,Am,T,C,Ct,Sf,Tp,Ce } \\
\text { A,Am,T,C,Ct,Sf,Tp,Ce } \\
\text { A,Am,T,C,Sf,Tp,Ce } \\
\text { A,Am,T,C,Ct,Sf,Tp,Ce } \\
\text { A,T,Ct } \\
\text { A,Am,T,C,Ct,Sf,Tp,Ce } \\
\text { T,C,Sf } \\
\text { G,T,C,Sf,Tp }\end{array}$ \\
\hline
\end{tabular}

a Jan, January; Feb, February; Dec, December

b Antimicrobial agents: A, ampicillin; Am, amoxicillin; G, gentamicin; T, tetracycline; C, chloramphenicol; Ct, colistin sulphate; Sf, sulfamethoxazole-trimethoprim; Tp, trimethoprimsulpanimide; Ce, cefoperazone.

"Sporadic isolates, Mth = month, $\mathrm{Yr}=$ year, RNDC = React but did not conform with any phage pattern, UT= Untypeable

\section{Results}

Phage typing of the $19 S$. Typhimurium strains revealed that $11(57.9 \%)$ strains belonged to DT71 phage type, 5 to RDNC, and 3 (sporadic strains) to UT phage type. Out of 11 DT71 strains, 5 (45.5\%) were identified in humans and $2(18.2 \%)$ each from sewage, cattle and water (Table).

The PFGE of Xbal-digested chromosomal DNA from $19 \mathrm{~S}$. Typhimurium strains gave stable and reproducible patterns. The dendrogram analysis of the isolates showed three clusters of 4 PFGE (Figure
1). The first cluster consisted of PFGE types $X 1$ and $\mathrm{X} 2$ with $96.8 \%$ similarity. The second comprised PFGE type X3, and the third was made up of PFGE type $\mathrm{X} 4$. The overall level of genetic relatedness for the strains was $71.0 \%$ similarity. PFGE type X3 $(57.9 \%)$ was the most prevalent, identified among five $(41.7 \%)$ human, two $(100 \%)$ water, two $(66.7 \%)$ sewage and two (100\%) cattle isolates, and they were resistant to different antibiotics One strain from a water sample, which shared the same resistance pattern with a strain from a sewage sample, belonged 
to DT71/X3 phage/PFGE type (Table). Five RDNC phage type strains (four from humans and one from sewage) exhibited A, Am, G, T, C, Sf, Tp, and Ce resistance patterns with or without $\mathrm{Ct}$, and belonged to PFGE types X1 and X2 (Table and Figure1). The three sporadic strains which belonged to UT phage type presented PFGE type X4 and were resistant to ampicillin and/ orgentamicin. Five of the $13 \mathrm{~S}$. Enteritidis strains were untypeable (UT), seven belonged to RDNC, and a strain which belonged to PT29 was isolated from water. Digestion of the 13 isolates with Xbal restriction enzymes revealed 11 to 16 fragments. The dendrogram of the isolates revealed three clusters of four PFGE (Figure 2). The first consisted X1e, the most prevalent type $(61.5 \%)$, identified in seven of the eight $(87.5 \%)$ human strains and a strain from sewage. The second comprised PFGE types X2e and X3e with $80 \%$ similarity, identified in two human isolates. The third PFGE type $\mathrm{X} 4 \mathrm{e}$ was identified in one and two isolates of animal and water origins respectively. The level of genetic relatedness recorded for all the strains was $64 \%$ similarity (Figure 2). Most $S$. Enteritidis strains evaluated in this study were multidrug resistant and belonged to PFGE type X1e (Table).

\section{Discussion}

Epidemiological investigations for routine surveillance and for examining the strains that cause disease outbreaks are important in medical settings. Such data allow public health officials the ability to determine if the causative organisms are part of the transient or resident populations. The results of phage typing of $16 S$. Typhimurium outbreak-related strains revealed that $68.8 \%$ belonged to DT71, identifying it as the most prevalent phage type in this study. DT71 Typhimurium is a rarely reported phage type in literature and this is the first of its kind in Nigeria, as reported in our previous publication [24]. In an African country such as Kenya, genetic variations among different phage types in $S$. Typhimurium strains have been documented, thus suggesting diversification of serovar Typhimurium [25].

PFGE analysis of $19 \mathrm{~S}$. Typhimurium isolates (including three sporadic isolates) revealed a high degree of genetic homogeneity among isolates of the same phage type, with PFGE type $\mathrm{X} 3$ predominating, and featuring in $11(57.9 \%)$ of the isolates. Interestingly, $11(68.8 \%)$ of the 16 suspected outbreak-related strains belonged to DT71 phage type and were genetically related to common PFGE type

Figure 1. Dendrogram (Left panel) and DNA fingerprints (Right panel) of 19 S. Typhimorium strains generated by the GelCompar II software

Dice (Opt:1.00\%) (Tol 1.0\%-1.0\%) (H>0.0\% $S>0.0 \%)[0.0 \%-100.0 \%$

PFGE-Xbal PFGE-Xbal

Isolate No PFGE type Phage type

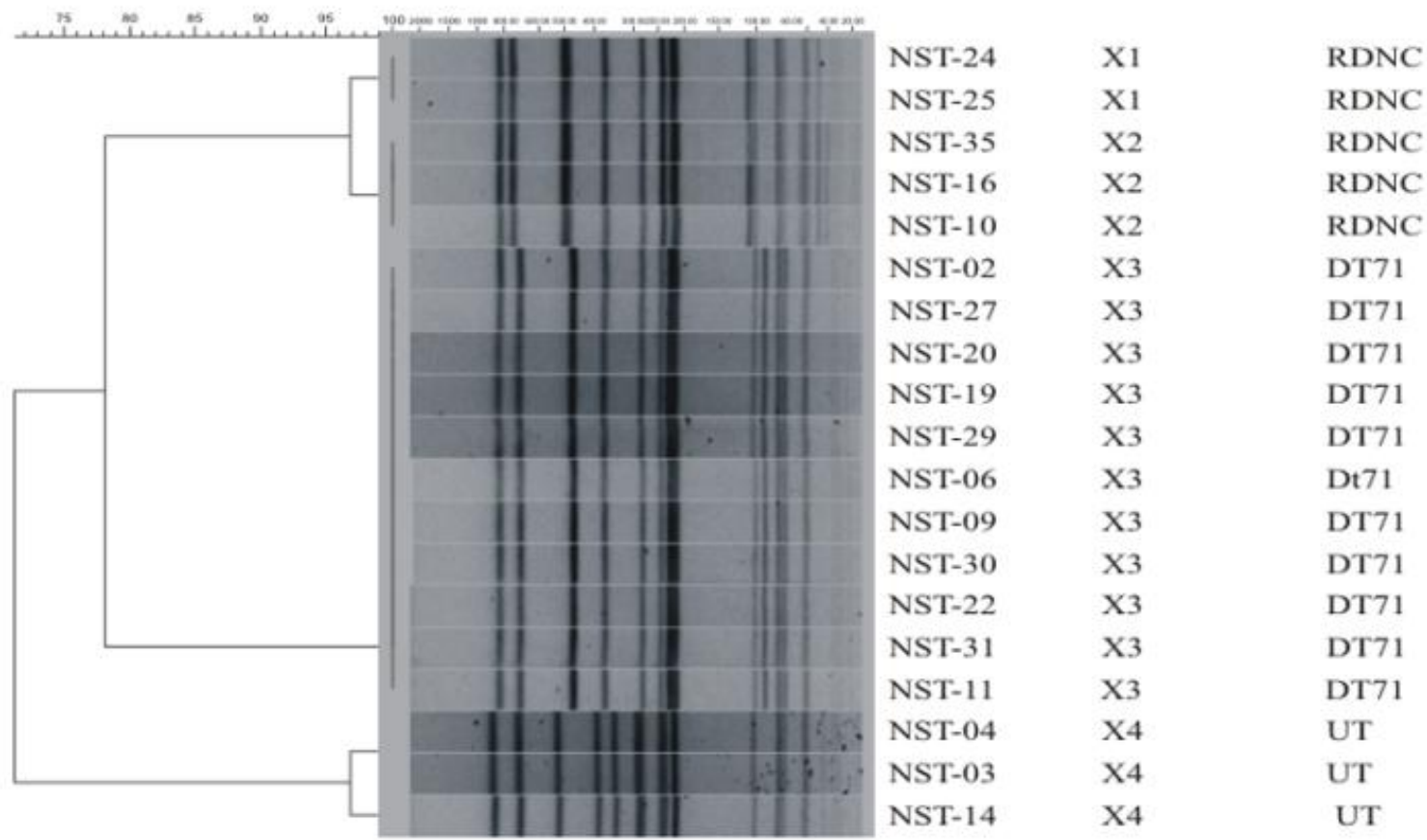


$\mathrm{X} 3$. However, five of the 11 strains with the DT71/X3 combination were isolated from patients. Two DT71 strains each isolated from well water, cattle, and sewage were found to share the same PFGE type X3 with these humans strains (Table). This observation was an indication of sewage as a possible source and well water as a route of transmission of infection in five of the patients with gastroenteritis in the community affected in the suspected outbreak. None of the strains in this study was resistant to ciprofloxacin, ofloxacin and perfloxacin antibiotics, but a major concern of $S$. in this community who were affected in the suspected outbreak. However, RDNC phage type has been reported among $S$. Typhimurium isolates in a study conducted by Onyango et al. (25) in Maseno, Kenya. All the RDNC strains in this study belonged to two closely related PFGE types X1 and X2 (96.8\% similarity) with a difference of one fragment in their binding patterns, and they were resistant to seven or more antibiotics (Table). The slight difference observed in the two PFGE types among the five strains may be due to a small genetic element (e.g., plasmid) possibly acquired by the strains, or perhaps

Figure 2. Dendrogram (Left panel) and DNA fingerprints (Right panel) of 13 Salmonella Enteritidis strains

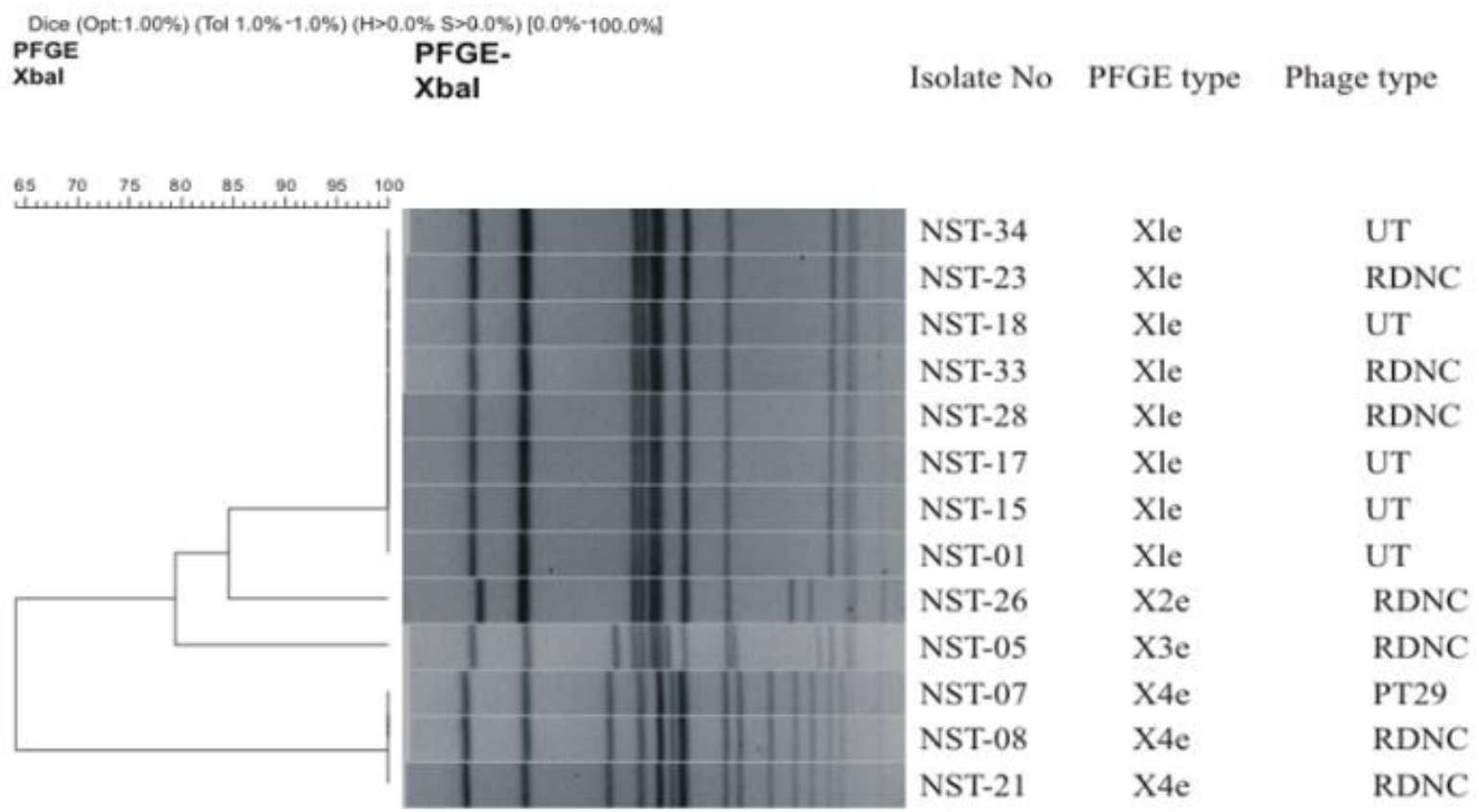

Typhimurium DT71 is the multiple drug resistance exhibited, particularly among the human strains (Table). Like $S$. Typhimurium DT104, which is chromosomally encoded penta-drug resistant (26), the infection with DT 71 seems to follow a severe clinical course because all five patients involved in the suspected outbreak suffered acute gastroenteritis that lasted between five and eight days, an indication of a threat posed by $S$. Typhimurium DT71 to public health. Furthermore, a strain (NST-10) isolated from another sewage source within a $500 \mathrm{~m}$ radius of the cases shared common phage type RNDC with four strains isolated from the patients with gastroenteritis to small insertion or deletion events that had taken place within a short period. The appearance of different genovars within Salmonella serovars due to insertion and deletion events have been reported to occur within a relatively short time; at the same time, factors such as (i) serogroup, (ii) host specificity, and (iii) disease characteristics are known to influence the clustering of isolates [27]. In fact, fingerprinting by PFGE indicated that all three sporadic strains (NST03, NST04 and NST14) belonged to the same cluster of PFGE type X4 (Figure 1). Since these strains were isolated from cases of human gastroenteritis at distant periods, this result may 
further attest to the sensitivity of PFGE in discriminating between epidemiologically unrelated and outbreak-related $S$. Typhimurium strains [13].

Xba1 analyses of 13 suspected outbreak-related $S$. Enteritidis strains revealed three clusters of four PFGE types. PFGE X1e was the predominant type, identified in eight of $13 \mathrm{~S}$. Enteritidis strains, seven of which were from human origins and one strain (NST17) from a water sample. The eight $S$. Enteritidis strains were found to be identical by PFGE and were believed to have derived from a common source, an indication that the well water, where the NST17 strain was isolated, served as a possible source of the $S$. Enteritidis-associated gastroenteritis. Also, a strain (NST08) from cattle within the same sampling zone was genetically different but highly related to two strains (NST07 and NST21) isolated from other well water samples in the same area. It has been documented that indistinguishable strains could be recovered from a large number of sources [28]. What is interesting is that most of the $S$. Enteritidis strains are either RDNC or untypeable by phage, which could be a new phage type causing a micro-epidemic in this community. Only one of the strains of $S$. Enteritidis studied belonged to a defined phage type PT29 and was isolated from well water within a $500 \mathrm{~m}$ radius of the cases. The fact that PT29 was not isolated from any of the patients affected in the supposed outbreak did not rule out the health hazard associated with this strain in this community.

The present study was hospital-based and close observations showed that most of the patients had been on antibiotic self-medication. In other parts of the world, different phage types appear to predominate in $S$. Enteritidis. For example, PT4 is known to be the most common in England [11], Germany [29], and Italy [30], while PT6 is most common in Denmark, PT8 in Poland and Slovak Republic, PT1 in Russia and Hungary, and PT8 and PT 13a in the United States of America [31,32]. Generally, lack of data on Salmonella phage types in Nigeria make the basis for comparison difficult and thus one could underestimate the prevalence and risk associated with these strains of Salmonella isolates; however, phage profiles categorized as types 1, 3 and 5 in $S$. Typhimurium have been documented in Kenya [25].

In conclusion, despite the small sample size, our finding revealed that PFGE to a certain extent was able to trace and link the upsurge in the Salmonella- associated gastroenteritis in this community to well waters and a dirty environment. With regard to future works, it is important to confirm the true extent of genetic diversity among human, animal and environmental isolates of Salmonella serotypes circulating in Nigeria and other parts of the world with a view to identifying emerging strains such as $S$. Typhimurium DT71 and P29 S. Enteritidis that are becoming more relevant in public health.

\section{Acknowledgement}

We are grateful to the management and personnel of the Robert Koch Institute, Wernigerode,Germany, for their support. We are particularly grateful to Dr. R. Prager and Dr. W. Rabsch for their technical assistance in pulsed-field gel electrophoresis and phage typing. We also thank Dr. R. Sting of Chemisches und veterrinärunterschungsamt, Stuttgart, for serotyping the isolates. This research was sponsorsed by Alexander von Humboldt (AvH) Stiftung/Foundation, Germany.

\section{References}

1. Payment P and Riley MS (2002) Resolving the global burden of gastrointestinal illness: a call to action. A report from American Academy of Microbiology, Washington DC, American Academy of Microbiology, 26 p.

2. Thong K, Ngeow Y, Altwegg M., Navaratnam P, Pang T (1995) Molecular analysis of Salmonella enteritis by pulsedfield gel electrophoresis and ribotyping. J Clin Microbiol 33: 1070-1074.

3. Wiesner M, Hidalgo M, Castaneda E, Agudelo C I (2006) Molecular Analysis of Salmonella Enteritidis and Typhimurium Clinical and Food Isolates by Pulsed-Field Gel Electrophoresis in Bogota, Colombia Microbe Drug Resist. 12: 68-73.

4. Glynn MK, Bopp C, Dewitt W, Dabney P, Dokhtar M, Angulo FJ (1998) Emergence of multidrug-resistant Salmonella enterica DT104 infections in the United States. N Engl J Med 338: 1333-1338.

5. Wright JG, Tengelsen LA, Smith KE, Bender JB, Frank RK, Grendon JH, Rice DH, Theissen AM, Gilbertson CJ, Sivapalasim S, Barrett TJ, Besser TE, Hancock DD, Angulo FJ (2005) Multidrug-resistant Salmonella Typhimurium in four animal facilities. Emerg Infect Dis 11:1235-41.

6. Thong KK, Cardano AM, Yassin RM, Pang T (1996) Molecular analysis of environmental and human isolates of S. typhi. Applied and Environ Microbiol 62: 271-274.

7. Mohammed I, Chikwem JO, Gashau W (1992) Determination by Widal agglutination of the baseline titre, for the diagnosis of typhoid fever, in two Nigerian States. Scan J Immunol 36: 153-156.

8. Oboegbulam SI, Oguike JU, Gugnanai HC (1995) MicroBiological Studies on cases diagnosed as typhoid/enteric fever in South-east. Nigeria J Commun Dis 27: 97-100.

9. Agbonlahar DE, Agbahowa MO, Idukpaye O, Agbonlahor FE, Ekundayo EO, Emeke FE, Osunined MI, Omoregbe R, Oyemelukwe NF, Okara GC (1997) Baseline typhoidal Antibody levels in Apparently Healthy Nigerians. Nig Qt J Hosp Me. 7: 242-245.

10. Akinyemi KO, Smith SI, Oyefolu AO, Coker AO (2005) Multidrug resistance in Salmonella enterica serovar typhi 
isolated from patients with typhoid fever complications in Lagos, Nigeria. Public Health 119: 321-327.

11. Ward LR, de Sa JDH, Rowe B (1987) A phage typing scheme for Salmonella enteritidis. Epidemiol Infect 99: 291304.

12. Threlfall EJ, Chart H, Ward LR, de Sa JDH, Rowe B (1993) Interrelationships between strains of Salmonella enteritidis belonging to phage types 4, 7, 7a, 8, 13, 13a, 23, 24 and 30 . J.Appl. Bacteriol 75: 43-48.

13. Laconcha I, Lopez-Molina N, Romenteria A, Audicana A, Perales I, Garaizar J (1998) Phage typing combined with pulsed-field gel electrophoresis and ramdom amplified DNA increases discrimination in the epidemiology analysis of Salmonella enteritidis strains. Inter J Food Microbiol, 40: 27-34.

14. Liebana E, Guns D, Garcia-Migura L, Woodward MJ, Clifton-Hadley FA, Davies RH (2001) Molecular typing of Salmonella serotypes prevalent in animals in England: assessment of methodology. J Clin Microbiol 39: 36093616.

15. Vesulovic J and Lapski JR (2002) Molecular detection and genotyping of pathogens: More accurate and rapid answers. Trends Microbiol 10: S15-S21.

16. Thong KL, Goh YL, Radu S, Noorzaleha S, Yasin R, Koh YT, Lim VK, Rusul G, Puthucheary SC (2002) Genetic diversity of clinical and environmental strains of Salmonella enterica serotype Weltevreden isolated in Malaysia. J Clin Med Microbiol 40: 2498-2503.

17. Woo YK (2005) Finding the sources of Korean Salmonella enterica serovar Enteritidis PT4 isolates by pulsed-field gel electrophoresis. J Microbiol 43: 424- 429.

18. Cowan ST and Steel S (1993) Identification of family Enterobacteriaceae. In Barrow GI and Feltham RKA (Editors), Manual for the Identification of medical bacteria. Cambridge: Cambridge University Press, p. 32.

19. Popoff MY, Bockemühl J, Gheesling LL (2004) Supplement 2002 (no.46) to the Kauffmann-White scheme. Res. Microbiol 155: 568-570.

20. NCCLS (2001) Performance Standards for Antimicrobial Susceptibility Testing: $11^{\text {th }}$ Informational Supplement. Approved Standard M2-A7 and M7-A5 National Committee for Clinical Laboratory Standards, Wayne, PA, USA.

21. Anderson S, Ward LR, de Saxe M.J, de Sa JDH (1977) Bacteriophage-typing designations of Salmonella typhimurium. J Hgy Camb 78: 297-300.

22. Rabsch W, Helm RA, Eisenstark A (2004) Diversity of phage types among archived cultures of Demerec collection of Salmonella enterica serovar Salmonella Typhimurium strains. Appl Environm Microbio70: 664-669.

23. Centres for Disease Control and Prevention (2004) Standardized Laboratory Protocol for Molecular Subtyping of Escherichia coli O157:H7, non-typhoidal Salmonella serotypes, and Shigella sonnei by Pulsed Field Gel Electrophoresis (PFGE). PulseNet PFGE Manual, Centres for Disease Control and Prevention, Atlanta, Ga, USA, Sec. 5.1, 5.2, 5.4. 1-13.

24. Akinyemi KO, Philipp W, Beyer W, Böhm R (2007) In vitro antimicrobial patterns of Salmonella enterica serovars and emergence of $S$. typhimurium phage type DT071 in a suspected community-associated outbreak in Lagos, Nigeria. J Infect Dev Ctries 1: 48-54.

25. Onyango MD, Ghebremedhin B, Waindi EN, Kakai R, Rabsch W, Tietze E, Konig W, Konig B (2009) Phenotypic and genotypic analysis of clinical isolates Salmonella serovar Typhimurium in Western Kenya. J Infect Dev Ctries 3: 685-694.

26. Poppe C, Ziebell K, Martin L, Allen K (2002). Diversity in antimicrobial resistance and other characteristics among Salmonella Typhimurium DT104 isolates. Microb Drug Resist 8: 107-122.

27. Porwollik S, Boyd EF, Choy C, Cheng P, Florea L, Proctor E, McClelland M (2004) Characterization of Salmonella enterica Subspecies I Genovars by use of Microarrays. J Bacteriol 186: 5883-5898.

28. Tassios PT, Markogiannakis A, Vatopoulos AC, Katsanikou E, Velonakis EN, Kourea-Kremastinou J, Legakis NJ (1997) Molecular epidemiology of antibiotic resistance of Salmonella enteritidis during a 7-year period in Greece. J Clin Microbiol 35: 1316-1321.

29. Schroeter A, Ward LR, Rowe B, Protz D, Hartung M, Helmuth R (1994) Salmonella enteritidis phage types in Germany. Eur J Epidemiol 10: 645-648.

30. Nastasi A, Mammina C, Fantasia M, Pontello M (1997) Epidemiological analysis of strains of Salmonella enterica serotype enteritidis from foodborne outbreaks occurring in Italy, 1980-1994. J Med Microbiol 46: 377-382.

31. Angulo FJ, Swerdlow DL (1999) Epidemiology of human Salmonella enterica serovar Enteritidis infection in the United States. In AM Seed (ed), Salmonella enterica serovar Enteritidis in humans and animals. Epidemiology, pathogenesis, and control. Ames: Iowa State University Press. p. 33-41.

32. Rabsch W, Tschape H, Baumler A J (2001) Non-typhoidal Salmonella: emerging problems. Microbes Infect 3: 237247.

\section{Corresponding author}

Akinyemi K. O. (PhD)

Department of Microbiology

Lagos State University

PMB 1087, Apapa

Lagos, Nigeria

Tel: + 2348029088676: 07034127529

Email: akinyemiko@yahoo.com

Conflict of interests: No conflict of interests is declared. 